\title{
Open Building as a Design Approach for Adaptability in Chinese Public Housing
}

\author{
Guopeng Li, Zhubin Li, Yanbing Li \\ School of Architecture and Fine Arts, Dalian University of Technology, Dalian, China \\ Email: liguopeng@dlut.edu.cn
}

How to cite this paper: Li, G.P., Li, Z.B. and $\mathrm{Li}$, Y.B. (2019) Open Building as a Design Approach for Adaptability in Chinese Public Housing. World Journal of Engineering and Technology, 7, 598-611. https://doi.org/10.4236/wjet.2019.74043

Received: September 11, 2019

Accepted: October 18, 2019

Published: October 21, 2019

Copyright $\odot 2019$ by author(s) and Scientific Research Publishing Inc. This work is licensed under the Creative Commons Attribution International License (CC BY 4.0).

http://creativecommons.org/licenses/by/4.0/ (c) (i) Open Access

\begin{abstract}
Surveys on public housing in Northern China indicated that the common aim of Chinese public housing, which is to provide affordable housing, had been mostly satisfied. However, more than one fourth (29.9\%) of the public housing units that were investigated were structurally modified by their occupiers for different layouts. This situation indicated that a fixed plan could not fulfill housing occupiers' various requirements on spacing layout, and critical awareness had been shown that the adaptability of the public housing units was always ignored. Open Building is well organized and implemented in the field of residential area to increase adaptability and sustainability of dwellings. This paper reviewed the development of residential Open Building and attempted to reveal solutions for the design of adaptability in Chinese public housing. Based on the dwelling unit types, dwelling spaces, living modes and demographic conditions of the public housing units were investigated; and concerning the actual carried out adaptations in the public housing units, this research explored two levels of design and control methods: prototyping unit for possible layouts and flexible partitions for space-function reconfiguration. By adding design values of adaptability in public housing, key aspects showing the potentials and challenges for the design of public housing were summarized for future reference.
\end{abstract}

\section{Keywords}

Chinese Public Housing, Adaptability, Layout, Flexible Partition, Open Building

\section{Introduction}

\subsection{Chinese Public Housing}

The soaring price of commercial housing makes Chinese government consider 
providing public housing for the low-income people after the housing commercializing reform in 1998. In China, the public housing generally refers to "low-rent housing (Lianzu fang), affordable housing (Jingji shiyong fang), and public rental housing (Gongzu fang)", which has different target groups. Those eligible lowest income people could apply for low-rent housing units or rent subsidies from the government. Affordable housing projects are built for those people of certain affordability, and cannot be exchanged in housing market unless the householder makes an additional payment to get the whole ownership of the housing unit. Public rental housing, emerged in 2009, aims to benefit the most low-income people through a relatively low rent (compared to common rental housing) and lenient requirements of eligibility (Figure 1).

Low-rent housing and affordable housing were the main components of public housing at the initial stage of the housing commercializing reform. They were proved to be effective to curb the soaring commercial housing price [1]. However, the insufficient fund and disorganized management make it hard to resolve the problem totally only by low-rent housing and affordable housing. Drawing on Hong Kong and Singapore's experience in public housing, Chinese government started to build public rental housing system. Now, public rental housing is widely believed a new efficient and effective way to meet the needs for a transitional accommodation of low-income people.

According to Chinese "The Outline of the 13th Five-year Plan for Urban and Rural Housing Development" [2], more than 42 million public housing units were started to construct and 28.6 million public housing units were completed and allocated to eligible families between 2011 and 2015; and from 2016 to 2020, it will continue to develop government-subsidized housing in urban areas, improve the housing system that encourages both purchase and rent, and vigorously develop the housing rental market. It indicates taht providing more public housing for low-income people is an important duty for Chinese government.

\subsection{The Issues}

In the development of public housing, however, there are still many issues waiting for solutions. In terms of building design, the key issue is that the initial design of unit layouts could not satisfy the needs of residents, according to the investigations carried out [3]. That leads to around $30 \%$ of residents adapted the

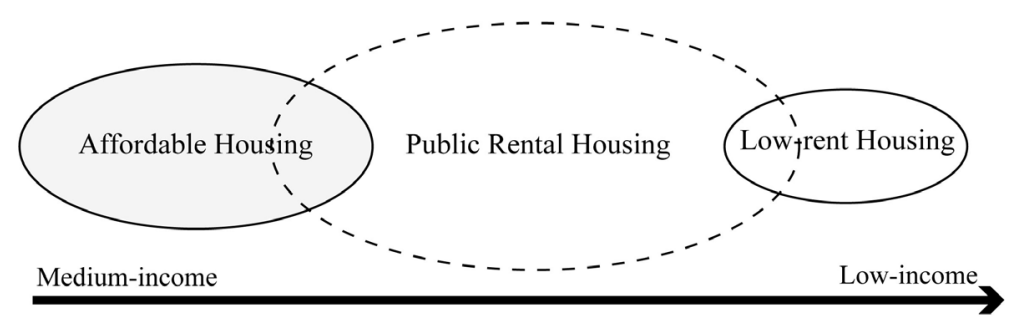

Figure 1. Relationship of three public housing types in China: Public rental housing fills the gap between affordable housing and low-rent housing, also could be accessed by those in waiting lists of the two types. 
internal layouts destructively by themselves based on their diverse needs. To improve residential satisfaction in public housing, providing an open and adaptable interior design might be the solution. It is also an effective method to reduce the constructional waste and save time, money and energy when interior modification is necessarily needed.

\section{Open Building in Design for Adaptability in Public Housing}

\subsection{Open Building as an Approach Dealing with Adaptability}

Open Building has been widely recognized as a multidisciplinary methodology applied in building design and industrialized construction that supports building adaptability according to different requirements.

Open Building is an important and systematic approach to design and construction for adaptability in terms of combining building components in such a way as to give optimal freedom of layout and installation [4] [5] [6]. Habraken first articulated the principles of Open Building in his book Supports an Alternative to Mass Housing, first published in Dutch in 1962 and in English in 1972 and 1999 [7]. In 1976, Habraken, together with J.T. Boekholt, A. P. Thyssen, and P. J. M. Dinjens, introduced a detailed Open Building design methodology in the book Variation: The Systematic Design of Support [8].

The concept of levels is the central idea of Open Building. Three levels of hierarchy are distinguished, these being tissue, support and infill. They are separated, yet coordinate. Higher levels serve as the setting and context in which lower levels operate. As such, higher levels of exercise dominance over lower levels, while lower levels are dependent on higher-level structures. The design professions, for their part, have evolved naturally in correspondence to the behavior of levels (urban planners, urban designers, architects and interior architects), each operating according to a certain level of intervention (Figure 2). Within a building system, the idea of levels is simply based upon separation of control between the support, which cannot be subject to the decision making of the individual user, and the infill, which is controlled by the individual inhabitant. Variations are subject to infill production and occupants' decisions.

Capacity analysis is the demanding practice at the core of design in Open Building. Capacity is defined as the measurable quality of a base building to accommodate a range of variations in floor plan and use within the constraints of a given base building $[10]^{1}$. Capacity analysis explores the degree of Open Building freedom offered by a higher level to a lower level. The dimensions, positions and interface of a lower level should be involved in the analyzing process to determine the higher level. Investigation on dwelling unit types, dwelling spaces, living modes and demographic conditions is the basis of capacity analysis. For instance, in designing the Support, the possibilities of space and function, zone, and sector should be carefully analyzed in order (Figure 3).

${ }^{1}$ The concept and explanation of Capacity was originally described in Kendall's book Residential Open Building, and was adjusted into a short version definition in this paper by the author. 


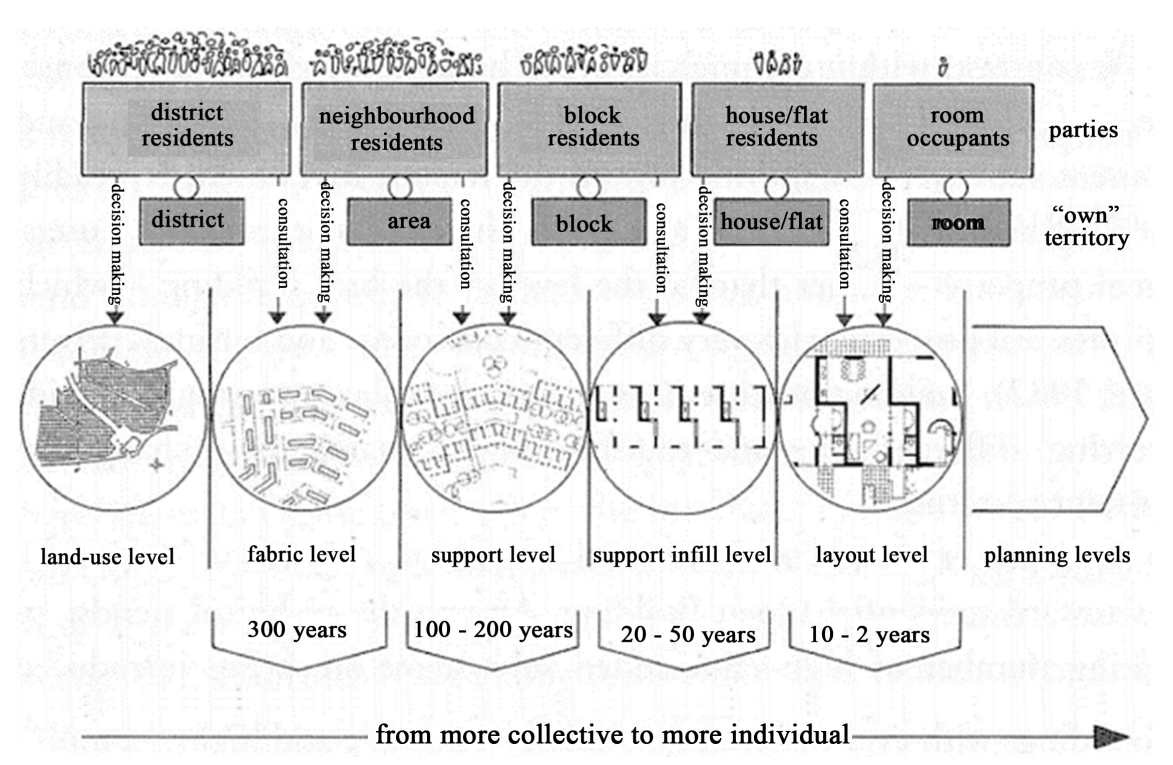

Figure 2. Principle of levels (from OBOM, TU Delft, 1990; [9] p. 91).
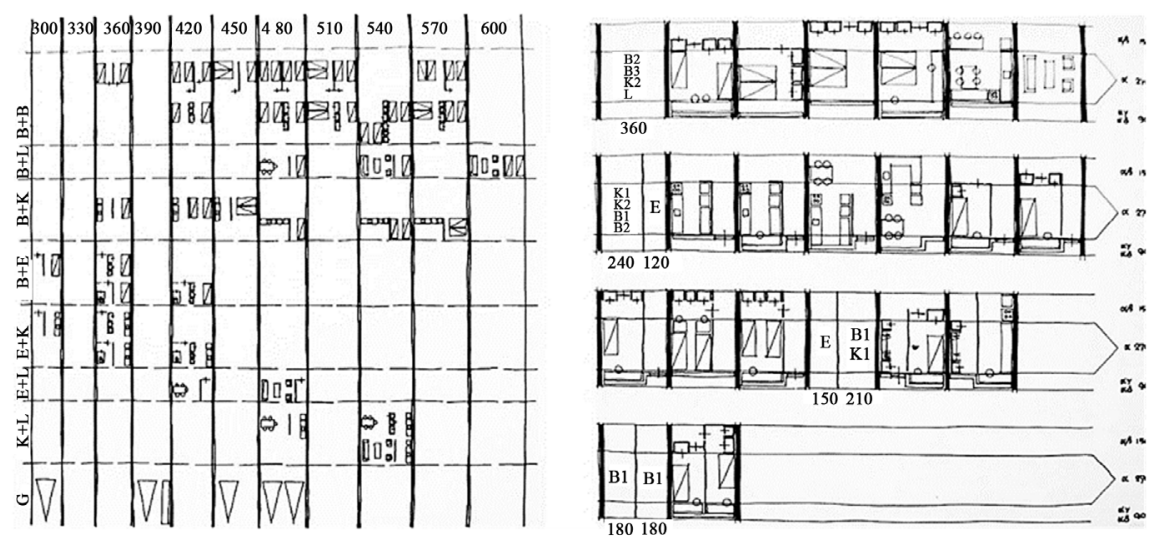

Figure 3. Capacity analysis: left, space and function analysis ([8] p.82: certain space accommodates certain functions, so that different layouts of functions that are defined by the furnitures are analysied to indicate a range of dimensions of spaces); right, sector analysis. ([8] p. 88: a certain combination of functions can be realised in a Sector, so that layout variations are illstrated in a certain Sector to accommendate different functional combinations. A Sector analysis is made to evaluate the ways in which it can be used.)

Open Building method is also characterized by non-structural infill assembled by the occupant in Zones and Margins within a general Support Structure [11]. The method systematically divided the Support into spaces designated as Zones, Margins, and Sectors, which are a precise means of delineating territory of similar location and dimension in the Infill. Figure 4 captures the basic principles of Open Building to realize variations.

\subsection{Design for Adaptability in Public Housing}

Summarizing the Open Building method, a diagram (Figure 5) showing the procedure of design for adaptability in public housing can be presented. 


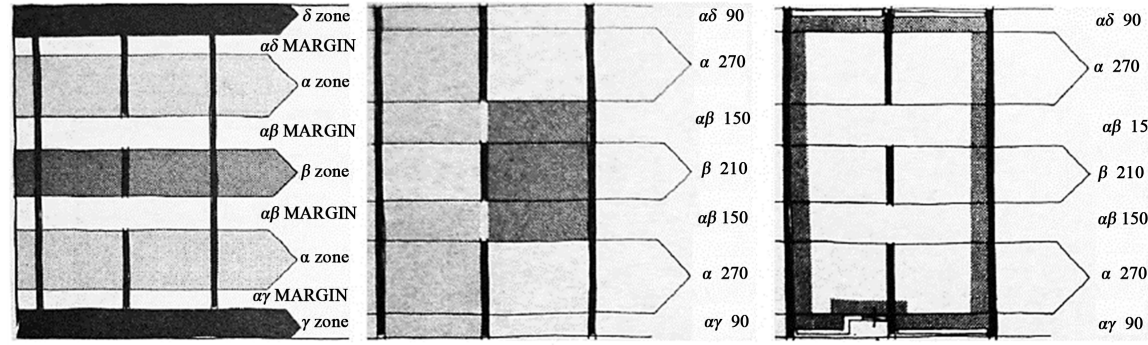

Figure 4. Principles of Open Building methodology: left: Zones and Margins([8] pp.108: a system of Zones and Margins form a Zone Distribution, which indicates spaces private or public, internal or external, and adjacent to an external wall or not. It is related to the capacity analysis space and function analysis, shown in Figure 3 left.); middle: Sectors ([8] pp.110: a Sector is a part of a Zone and its adjoining Margins that can be planned freely. The capacity analysis of a Sector is shown in Figure 3 right); right: a Sector group ([8] pp.110: a Sector group is a combination of connected Sectors, and it is also indicated/contrained by the relevent parts of the Support).

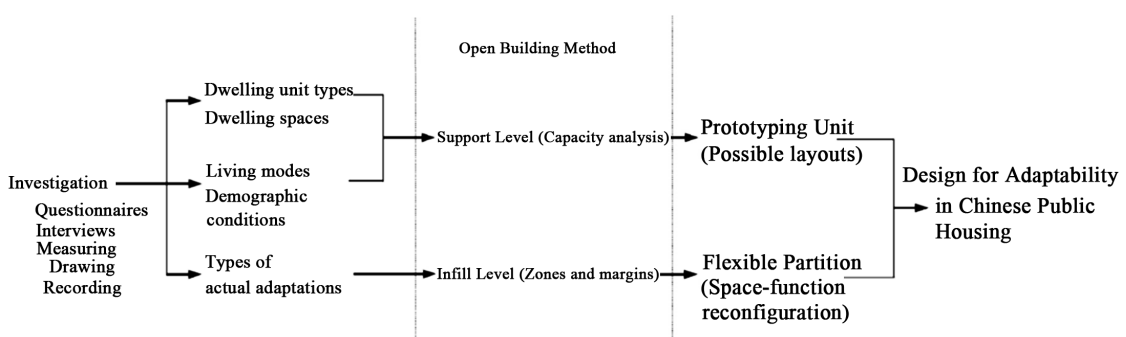

Figure 5. The procedure of design for adaptability with open building method.

\section{Investigation on Public Housing}

For collecting useful information about Chinese public housing and understanding how residents use and adapt their homes, a survey was conducted within 297 families in Northern China, most of which are in Shenyang and Dalian City. The dwelling unit types, dwelling spaces, living modes and demographic conditions of the public housing units were investigated, meanwhile concerning the actual adaptations carried out. The socio-geographic attributes were investigated through questionnaires and interviews, and are shown in $\mathrm{Ta}$ ble 1.

The dwelling unit types and dwelling sizes were measured and sketched by the interviewers and the corrected and redrawn with AutoCAD. In general, one dwelling unit composes of a living room, a kitchen, a bathroom and one or two bedrooms, and all the dwelling units investigated were designed and controlled within $60 \mathrm{~m} 2$ according to the local regulations. As mentioned, around $30 \%$ (80/268) of the internal layouts were adapted by the occupants. These modifications are made mainly based on three reasons. Twenty-nine percent (23/80) of the modifications is to get one more room or space through building a partition in the living room. The new room or the separated space would be used as a bedroom (16/23), or a kitchen (7/23). Around 50\% (38/80) of the modifications is to get a wider room by getting rid of inner walls: combining the living room 
with a kitchen (22/38) is the most popular modification in this group. Fourteen out of eighty families changed the position of inner walls to adjust the size of a certain room. Figure 6 and Figure 7 present examples of collected public housing information in Shenyang Anmin Community and Dalian Dayouqingchun Apartment.

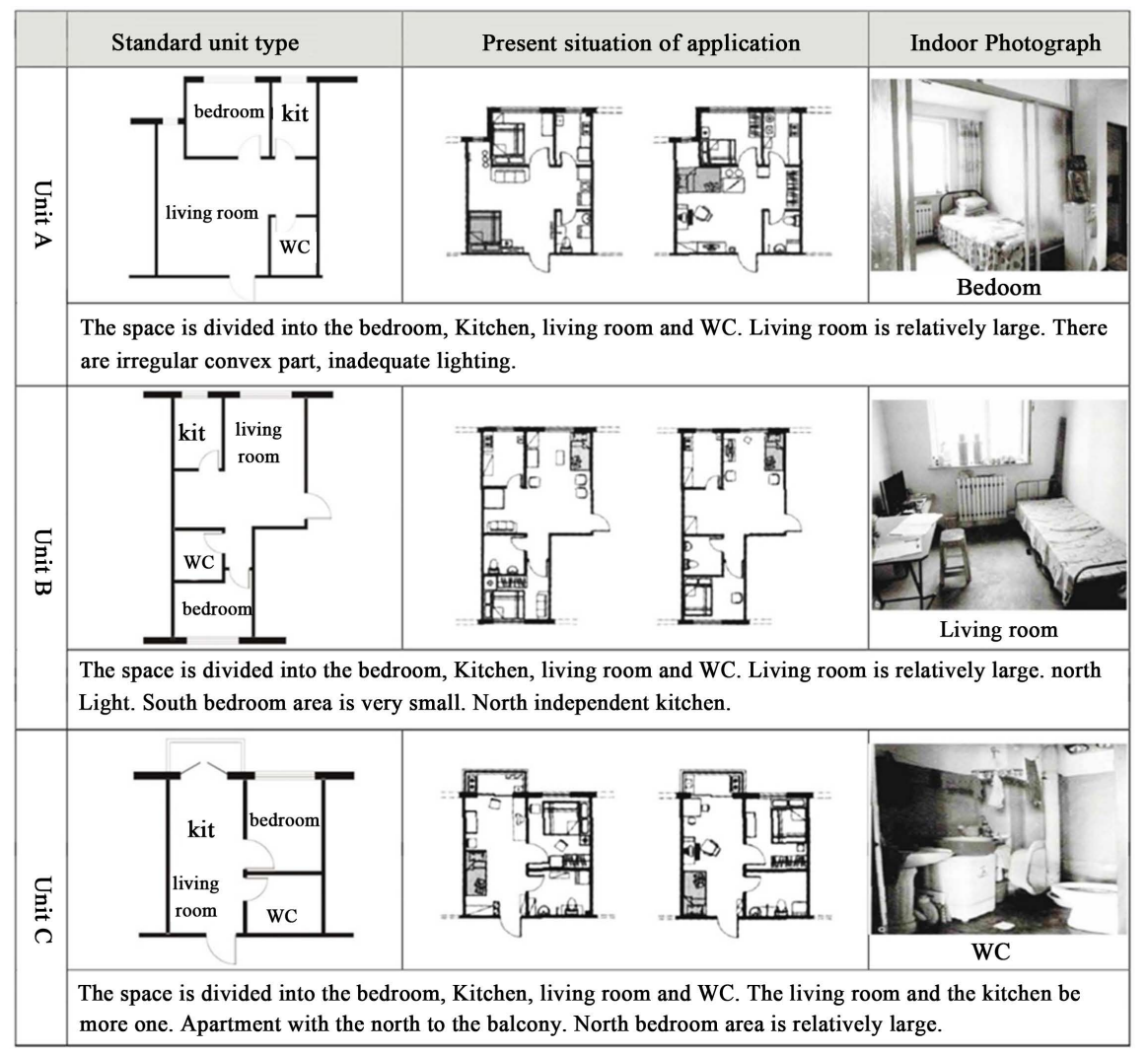

Figure 6. Shenyang Anmin Community public housing model information.

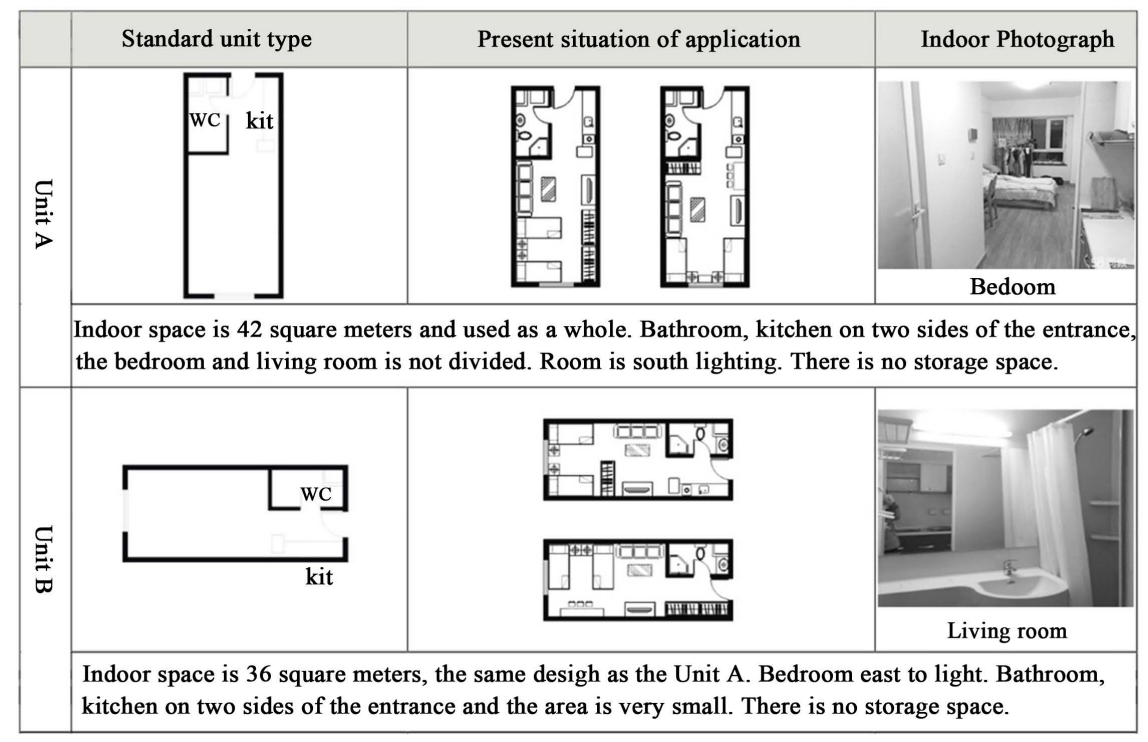

Figure 7. Dalian Dayouqingchun Apartment public housing model information. 
Table 1. Demographic characteristics of the respondents $(n=297)$.

\begin{tabular}{|c|c|c|c|c|c|}
\hline Characteristics & $\mathrm{n}$ & $\%$ & Occupation & $\mathbf{n}$ & $\%$ \\
\hline \multicolumn{6}{|l|}{ Age } \\
\hline $20-29 \mathrm{yr}$ & 25 & 8.4 & Worker in state-owned enterprises & 23 & 7.8 \\
\hline $30-39 \mathrm{yr}$ & 44 & 14.8 & Worker in private enterprises & 47 & 15.9 \\
\hline $40-49 \mathrm{yr}$ & 76 & 25.6 & Civil servant & 15 & 5.1 \\
\hline $50-59 \mathrm{yr}$ & 91 & 30.6 & Freelance worker & 69 & 23.3 \\
\hline $60-69 \mathrm{yr}$ & 33 & 11.1 & Retired worker & 74 & 25.0 \\
\hline Over 70 yr & 28 & 9.4 & Student & 1 & 0.3 \\
\hline Total & 297 & & No job & 67 & 22.6 \\
\hline Family type & & & Total & 296 & \\
\hline Single person & 42 & 14.1 & Educational level & & \\
\hline Couple only & 69 & 23.2 & Elementary school certificate & 14 & 4.7 \\
\hline $\begin{array}{l}\text { Couple living with their } \\
\text { child (ren) }\end{array}$ & 114 & 38.4 & Middle school certificate & 144 & 48.6 \\
\hline $\begin{array}{l}\text { Lone parent living with } \\
\text { his/her child (ren) }\end{array}$ & 28 & 9.4 & High school certificate & 70 & 23.6 \\
\hline $\begin{array}{l}\text { Couple living with their } \\
\text { parents and child (ren) }\end{array}$ & 26 & 8.8 & College or university's degree & 29 & 9.8 \\
\hline Other families & 18 & 6.1 & Professional school graduate & 24 & 8.1 \\
\hline Total & 297 & & No formal education & 15 & 5.1 \\
\hline Family size & & & Total & 296 & \\
\hline 1 member & 32 & 10.8 & Per capita monthly income ${ }^{*}$ & & \\
\hline 2 members & 95 & 32.0 & Less than 500 Yuan & 77 & 26.8 \\
\hline 3 members & 127 & 42.8 & $500-1000$ Yuan & 63 & 22.0 \\
\hline 4 members & 27 & 9.1 & $1000-1500$ Yuan & 69 & 24.0 \\
\hline 5 members and more & 16 & 5.4 & $1500-2000$ Yuan & 29 & 10.1 \\
\hline \multirow[t]{2}{*}{ Total } & 297 & & More than 2000 Yuan & 48 & 16.7 \\
\hline & & & Total & 287 & \\
\hline
\end{tabular}

\section{Capacity Analysis for Possible Unit Layouts on Support Level}

The capacity analysis is determined by the dimensions, positions and interface of the spaces and functions. Thus, the housing units investigated were firstly disassembled to individual spaces and functions. Those spaces and functions were measured and compared. Strong patterns can be found, due to the compact shape of each dwelling unit and the tight restriction about the dwelling size, that the similar functional spaces share similar spatial dimensions; meanwhile the width or depth of different functional spaces have a fair chance of overlapping the dimensions. In combination with considering the variable scope of each functional space being of the most commonality, a diagram of spatial dimensions can be presented (Figure $8 \mathrm{left}$ ). Then, because of the requirements of 

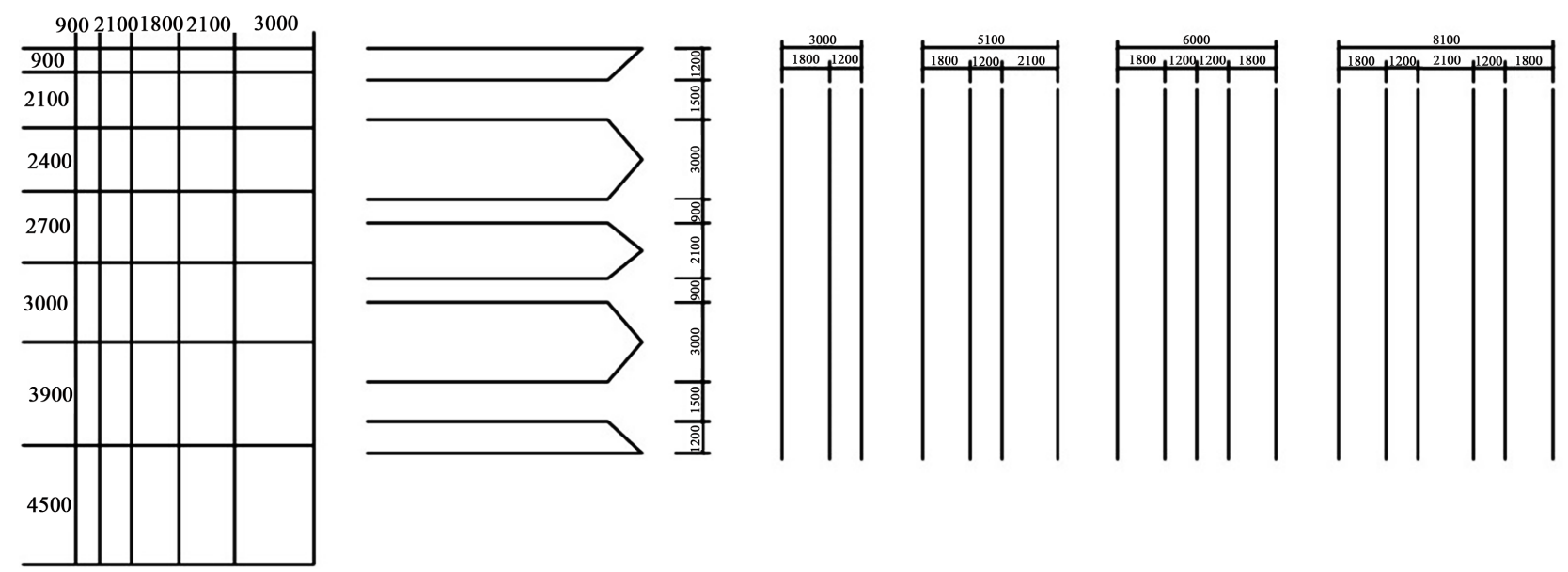

Figure 8. Capacity analysis: left, dimensions of functional spaces; middle, disposition along the depth of housing units; right, four types of width dimensions.

lighting and ventilation, the positions and interface of the functional spaces can be easily determined. The spaces away from the external walls have the worst condition to access natural lighting and ventilation, thus, the area ratio should be reduced and the spaces are usually used as auxiliary functions, such as a bathroom or a kitchen. And if a visual barrier is not necessary, the interface between the auxiliary spaces and the main functions can be ambiguous (Figure 8. middle). Finally, the dwelling size is basically determined by the width of the dwelling unit. Four types of width dimensions can be distinguished from $3 \mathrm{~m}$ to $8.1 \mathrm{~m}$ (Figure 8 right).

In accordance with the results from capacity analysis, a design procedure can be clearly generated from the axis range, dwelling unit boundary, prototyping, to possible layouts within a boundary. Figure 9 shows the procedure: the prototypes are designed on the basis of existing typical floor plans and unit combination forms; the possible layouts are proposed based on one of the prototypes, considering the living modes and demographic conditions from the investigation, as well as fulfilling the requirements of pertinence and adaptability for a specific family.

\section{Flexible Partitions for Space-Function Reconfiguration on Infill Level}

According to the protocol, it is strictly forbidden for the public housing tenants to alter the unit layout. This restriction makes it difficult to increase the adaptability of public housing if the internal walls are fixed, even though the units are designed intentionally for more possibility. Infill systems are developed, as a key part of the Open Building Method, to accommodate a variety of uses, of various sizes and layouts.

Stephen Kendall's MATRIXTILE and CABLESTUD system is one of the key explorations of the infill system for space-function reconfiguration. The MATRIX TILE [12] (Figure 10) is a solid material (e.g. medium density polystyrene) 


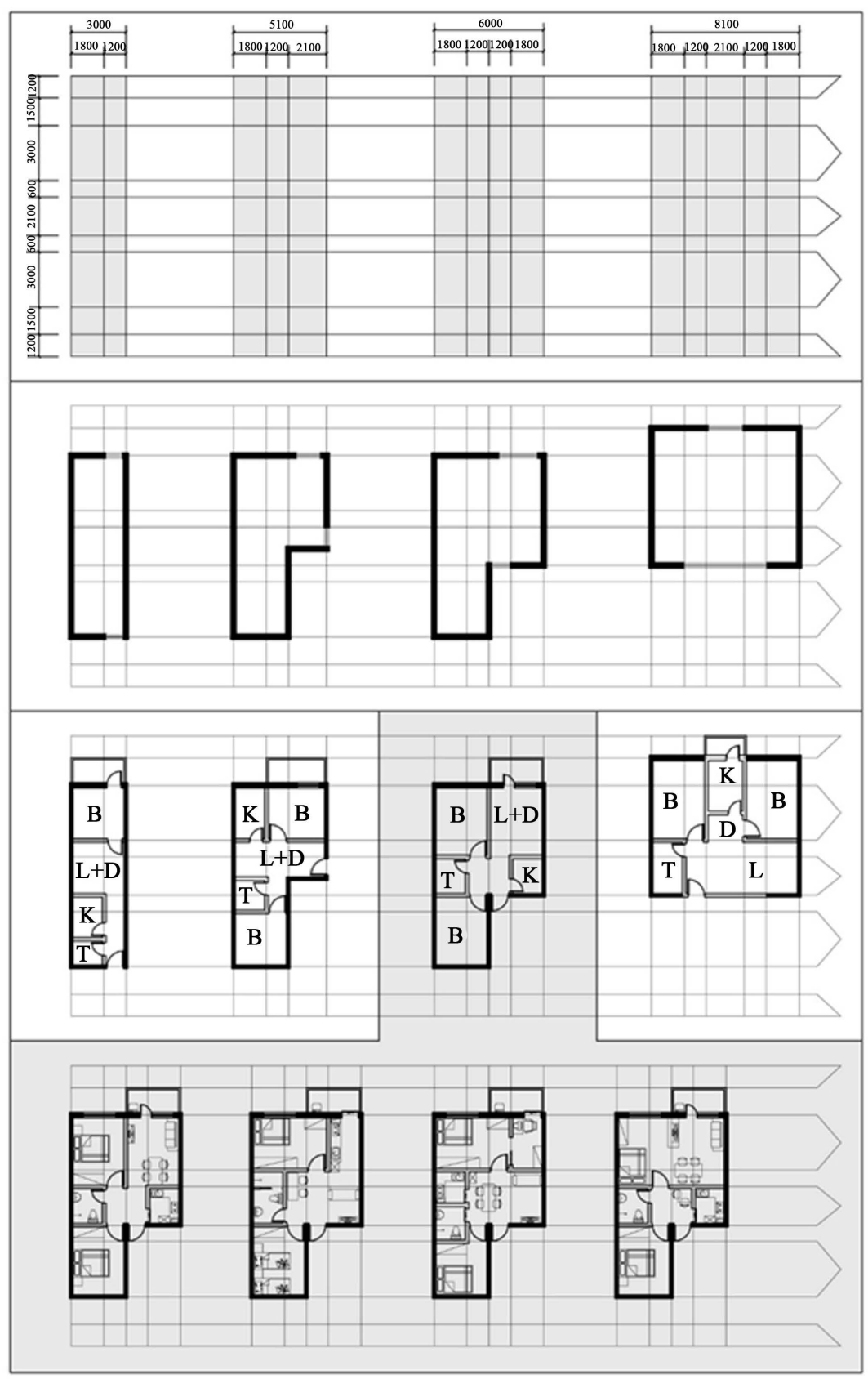

Figure 9. Prototyping and possible layouts.
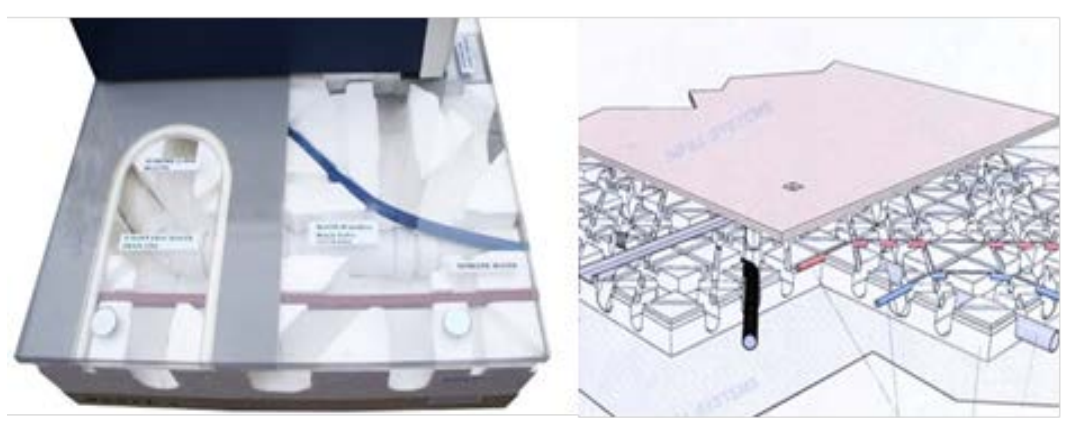

Figure 10. Matrix tile system. 
applied on top of the leveled base building floor. The tile thickness is approximately four inches. Grooves of various sizes and located in several horizontal "zones" allow the secure placement, without interference, of lines or conduits for various services, such as hot and cold water lines, gray-water drain lines (0-slope), hydronic heating pipes to radiators, floor heating, flat ventilation ducts, gas pipes and so on. This "tile" is covered by a one-inch-thick fire proof floor layer, after lines and conduits are installed. The MATRIX TILE SYSTEM assures rapid and accurate piping installations and maximum floor plan variety within a demised space. CABLESTUD [13] (Figure 11) is a patented product made of fiber reinforced fire retardant plastic, and has passed acoustical and structural/stress tests. It inserts into the bottom of typical non-structural metal studs, or in a notch at the bottom of a wood stud, providing for rapid installation of electrical and data cabling with connections made behind a removable baseboard. Installation of the electrical and data cabling, boxes and devices can take place in one efficient operation following erection of the metal studs and gypsum board.

The idea of changing layout by infill system space-function reconfiguration was also applied in the Next Home, designed by Avi Friedman as a triplex ${ }^{2}$, one of the Open Building projects in Canada. Due to its novelty of design and construction technologies, the floor plan has the potential to be divided and joined through flexible partitions (Figure 12).

As can be seen, flexible partitions are of great significance for infill systems. There are some types of flexible partitions in building industry. It can be divided into semi-fixed partition and movable partition according to their flexibility. The semi-fixed partition includes plate type partition, stud type partition, block type partition, and composite partition by their structure. The movable partition includes assemble type partition, sliding partition, folding partition, and scroll partition. Specific information is shown in Figure 13.

The above partition systems have many aspects in common, but they are also different in some specific aspects (unit cost, construction difficulty, etc.) For using in public housing, in addition to the division of space, flexible partitions
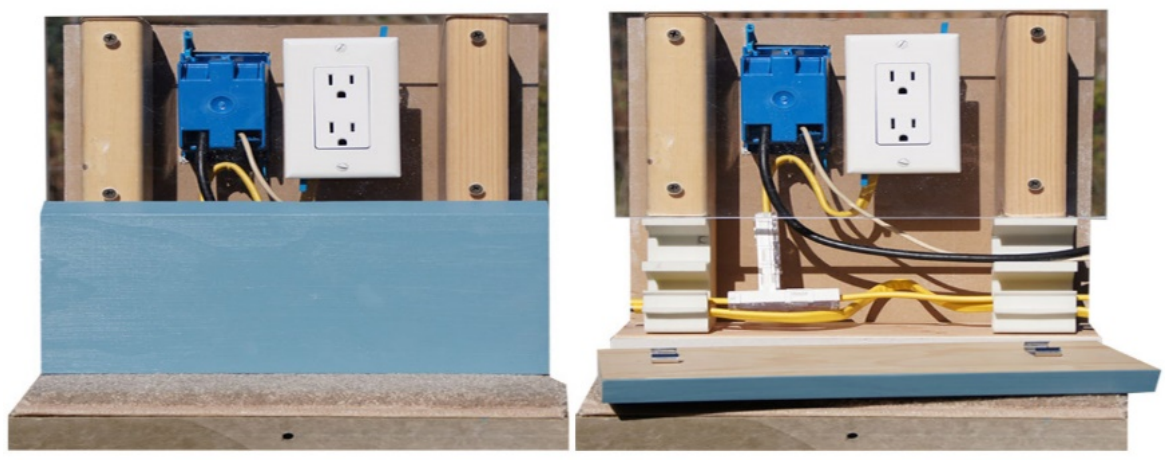

Figure 11. Cablestud.

${ }^{2}$ Triplex is defined by Avi Friedman as the housing typology that is designed and built as a house but has potential to be divided into up to three single units to realise affordability by process. The key examples are Next Home and Cite Jardin Fonteneau, both in Montreal. 


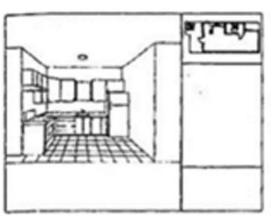

1. View of existing kitchen

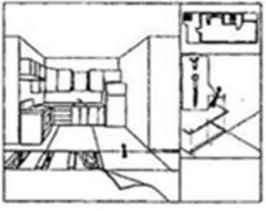

2. Remove floor covering and unscrew subfloor

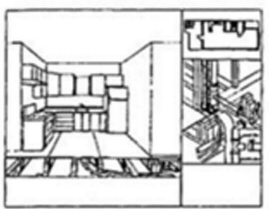

5. Disconnect mian drain pipes in chase

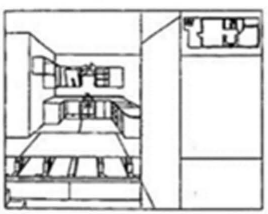

9. Reassemble kitchen in new location

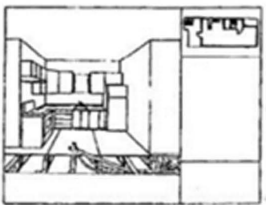

6. Remove disconnected drain pipe

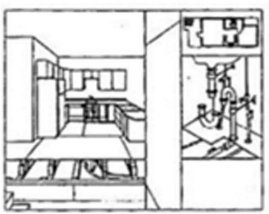

10. Connect drain pipe to sink

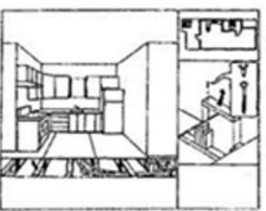

3. Dismantle joist bridge of plumbing chase

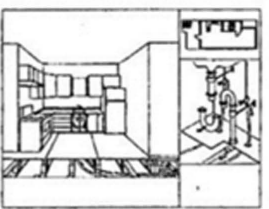

7. Disconnect kitchen sink drain pipes

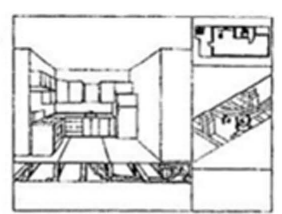

4. Disconnect drain pipes to sink

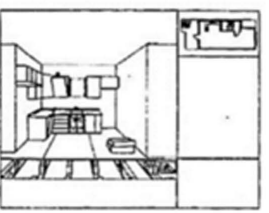

8. Disassemble kitchen

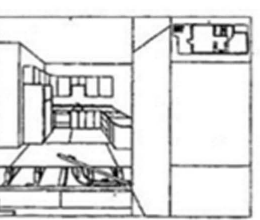

11. Place main drain pipe in chase

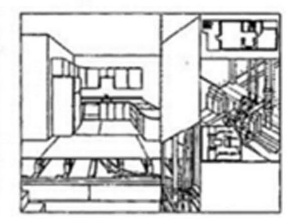

Connect main drain pipe to structure's drain

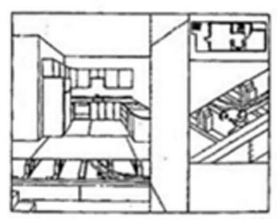

13. Connect sink drain to chase's drain

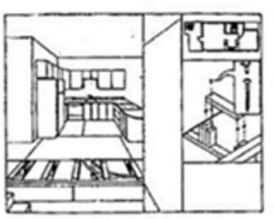

14. Place and screw the joist bridge

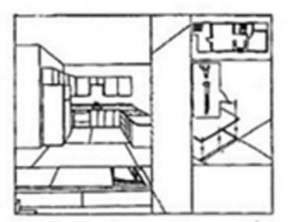

15. Screw back chase cover

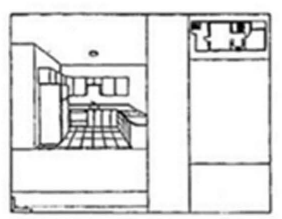

16. View of relocated kitchen

Figure 12. Next Home: user manual of step-by-step instruction on how to relocate a kitchen and manipulate the plumbing ([11] p. 175).

should also fulfill requirements on unit cost, difficulty of construction, space, fireproofing and sound insulation, the stability of stiffness and waterproof [14]. A simple quality assessment on the six indicators was carried out according to the existing data collection (Figure 14).

Plate type, stud type, block type partition is relatively low in cost; their sound insulation, fire waterproof is good; stiffness stability is strong. While the construction is more difficult, and sometimes wet operations are needed. In addition, since the thickness and characteristics of the semi-fixed partitions, the space occupied by them is relatively large. These features are particularly obvious in the block type wall. Assembly type, folding, sliding partition occupied small floor area and it is easy to assembly and disassembly. Little traces will be left on the wall and the ground after they are moved away. The plate can be 


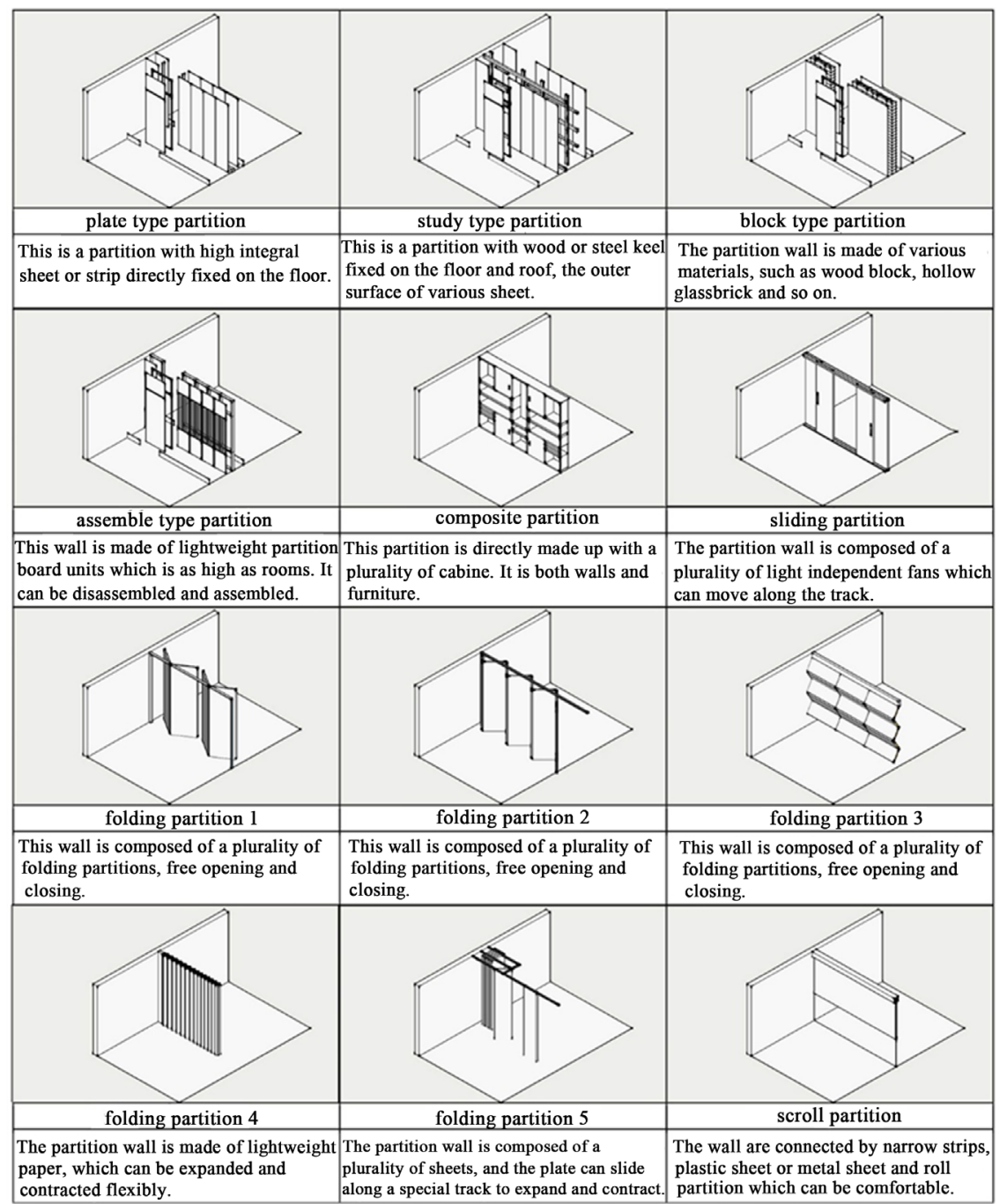

Figure 13. Types of flexible partitions.

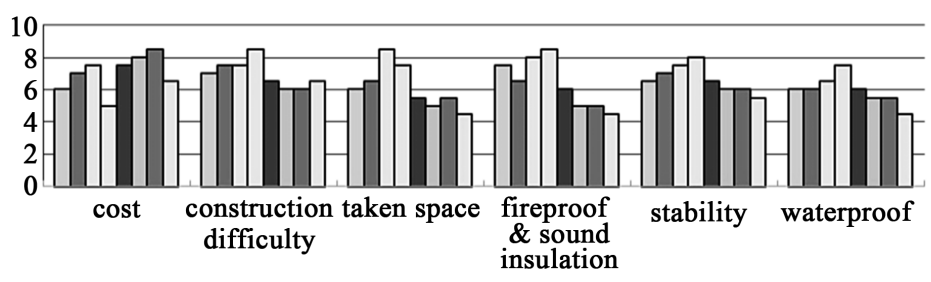

口plate type partition 口study type partition 口composite partition ablack type partition assemble partition $\square$ folding partition 口 sliding partition 口scroll partition

Figure 14. The evaluation of flexible partitions.

reused and the flexibility is high. But they are not as good as block type, stud type and plate type partition wall in fire proof, sound insulation, waterproof performance and unit cost. Composite partition is on a medium level in above aspects. But it can act as storage spaces and achieve good veneer decoration effect. Scroll partition has advantages in occupied space size, unit cost, construction difficulty, but it is poor in sound insulation, stiffness and stability, and waterproof. According to different characteristics of the flexible partition systems 
and the requirements of the public housing partition systems, the composite partition, assembly type partition and folding partition are more suitable for flexible division of the floor area in public housing.

\section{Conclusion}

The role of Chinese public housing is to promote and ensure the quality of living for low-income people in China; however, the massive destructive adaptations show the lack of consideration in adaptability. The significance of adaptability has been realized and providing an open and adaptable interior layout to improve the residential satisfaction becomes one of the key tasks in designing Chinese public housing. Design for adaptability with Open Building is a rigorous method built on surveys, analysis, and design. This paper, using Open Building method, developed and verified an approach of design for adaptability in Chinese public housing. Based on the investigations, a variety of living modes and demographic conditions can be fitted into the diversity of unit layouts developed from prototyping designs. Different types of flexible partitions were introduced and evaluated for selecting the suitable solutions of infill system for space-function reconfiguration. Based on this research, future studies could be related to undertaking practices, promoting technical services of infill system, and exploring the possible combination of dwelling units.

\section{Acknowledgements}

This work was supported by the National Natural Science Foundation of China (Grant No. 51638003 and 51808093) and Innovation Support Program for High-level Talents (Grant No. 2018RQ38).

\section{Conflicts of Interest}

The authors declare no conflicts of interest regarding the publication of this paper.

\section{References}

[1] Wang, X. and Zhao, F. (2009) Impact of Public Housing on the Price of Commercial Housing. Reform of Economic System, 5, 143-147.

[2] The 13th Five-Year Planning, Building and Construction Industry. http://news.dichan.sina.com.cn/2016/08/24/1212532 all.html

[3] Li, Z., Setoguchi, T. and Huo, K. (2013) A Study of Low-Rent Housing Room Usage and Its Inspiration on Public Housing Design. Architectural Journal, Academic Issue, 9, 180-185.

[4] Dekker, K. (1998) Research Information: Open Building Systems: A Case Study. Building Research \& Information, 5, 311-318. https://doi.org/10.1080/096132198369797

[5] Moharram, L.A. (1980) A Method for Evaluating the Flexibility of Floor Plans in Multistory Housing. Ph.D. in Architecture, University of Pennsylvania, Pennsylvania. 
[6] Bosma, K., van Hoogstraten, D., et al. (2000) Housing for the Millions: John Habraken and the SAR (1960-2000). NAI Publishers, Rotterdam.

[7] N. John Habraken Biography. https://www.habraken.com/html/biography.htm

[8] Habraken, N.J.. Boekholt, J.T., et al. (1976) Variations: The Systematic Design of Supports. Cambridge, Mass., Laboratory of Architecture and Planning at MIT. (English Translation by W. Wiewel and Sue Gibbons from the Original Dutch Publication: Denken in Varianten, Alphen a/d Rijn, Samson, 1974)

[9] Kendall, S. (2004) An Open Building Strategy for Achieving Dwelling Unit Autonomy in Multi-Unit Housing. Housing and Society, 31, 89-102. https://doi.org/10.1080/08882746.2004.11430500

[10] Kendall, S. and Teicher, J. (2000) Residential Open Building. E \& FN Spon, London.

[11] Friedman, A. (2002) The Adaptable House: Designing Homes for Change. Mc Graw-Hill, New York; London.

[12] MATRIX TILE SYSTEM. http://infillsystemsus.com/matrix-tile-system

[13] CABLESTUD. http://infillsystemsus.com/cablestud

[14] Li, G., Li, Y. and Li, Z. (2018) Application of Flexible Partition in Adaptive Housing Design. Architecture Technique, 2, 122-123. 